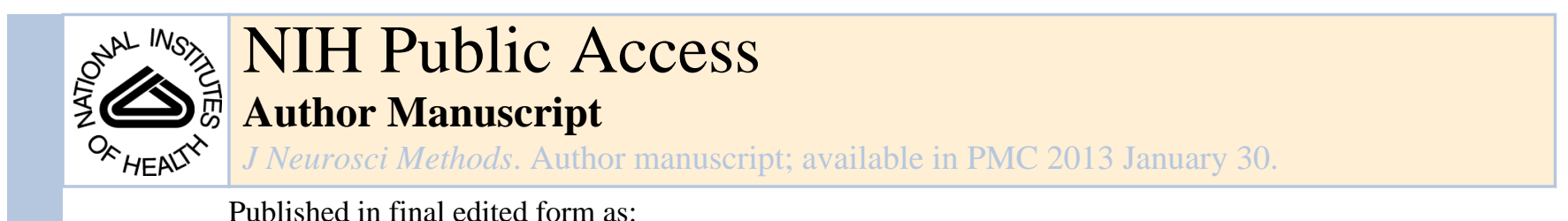

J Neurosci Methods. 2012 January 30; 203(2): 305-310. doi:10.1016/j.jneumeth.2011.09.030.

\title{
A novel computerized system for thermal stimulation of tooth in ferrets
}

\author{
Dong K. Ahn ${ }^{1,{ }^{*}}$, Ollie Monbureau ${ }^{2}$, Matti Narhi $^{3}$, and William Maixner ${ }^{4,}{ }^{*}$ \\ ${ }^{1}$ Department of Oral Physiology, School of Dentistry, Kyungpook University, Daegu, Korea \\ ${ }^{2}$ Department of Electronics, University of North Carolina, Chapel Hill, NC, 27599, USA \\ ${ }^{3}$ Biomedicine, Physiology, University of Eastern Finland, Finland ${ }^{4}$ Center for Neurosensory \\ Disorders, University of North Carolina, Chapel Hill, NC, 27599, USA
}

\begin{abstract}
A dual thermal and electrical stimulator was developed to examine the central pathways that transmit noxious stimuli for intact dentition. This system allows computer-controlled stimulation of the canines of ferrets with either noxious heat or electrical stimuli. A set of in vitro studies demonstrated that the application of thermal stimuli to an intact tooth can produce pulpal temperatures above $43^{\circ} \mathrm{C}$, which is perceived as a painful stimulus in humans. In a set of in vivo studies, it was demonstrated that heating an intact tooth at temperatures of at least $40^{\circ} \mathrm{C}$, excited trigeminal brainstem neurons. Only $15 \%$ of the neurons activated by electrical stimulation responded to noxious heat applied to the canine. Eight of the 23 neurons were classified as nociceptive specific neurons and responded only to noxious stimulation of their cutaneous receptive fields. Fifteen of the 23 neurons were classified as wide dynamic range neurons and responded to both noxious and non-noxious stimulation applied to their cutaneous receptive fields. This new device can accurately deliver both thermal and electrical stimuli to an intact tooth, which allows an evaluation of the central neural circuits that respond to noxious stimulation of the dentition.
\end{abstract}

\section{Keywords}

tooth pain; trigeminal nucleus; convergent neuron; dental stimulator

\section{Introduction}

Previous animal studies have shown that thermal stimulation of a tooth activates pulpal afferents (Matthews, 1977; Narhi et al., 1982). In addition, both hot and cold stimuli applied to an intact, non-diseased tooth, can also produce pain in humans (Naylor, 1963). On the other hand, the results of animal experiments are quite variable with regards to the threshold

\footnotetext{
(C) 2011 Elsevier B.V. All rights reserved.

*Correspondence: These authors contributed equally to this study as a corresponding author, Dong-Kuk, Ahn, Department of Oral Physiology, School of Dentistry, Kyungpook National University, 188-1, Sam Deok 2ga, Chung-gu, Daegu (700-412), Korea, Tel: 82-53-660-6840, Fax: 82-53-421-4077, dkahn@knu.ac.kr, William Maixner, Center for Neurosensory Disorders, University of North Carolina, Chapel Hill, NC, 27599, USA, maixnerw@ dentistry.unc.edu.

Publisher's Disclaimer: This is a PDF file of an unedited manuscript that has been accepted for publication. As a service to our customers we are providing this early version of the manuscript. The manuscript will undergo copyediting, typesetting, and review of the resulting proof before it is published in its final citable form. Please note that during the production process errors may be discovered which could affect the content, and all legal disclaimers that apply to the journal pertain.

The authors declare no conflicts of interest.
} 
and pattern of activity, and do not always appear to match the results from human studies (Anderson et al., 1970). It has been previously reported (Hu and Sessle, 1984) that the trigeminal neurons, which are excited by electrical stimulation of the tooth, do not always respond to natural stimuli (e.g., heat or cold) of tooth. This suggests that electrical stimulation of the dentition does not engage processes that mimic the events that produce dental pain evoked under clinical or natural conditions.

One of the primary functions of the trigeminal subnucleus caudalis (medullary dorsal horn) is to relay orofacial nociceptive information, including dental pain, to the more rostral regions of the central nervous system (Dubner and Bennett, 1983; Hu et al., 1981; Sessle, 1987). Electrophysiological studies have demonstrated that a large number of neurons in the medullary dorsal horn that respond to electrical stimulation of the tooth pulp (Nord, 1976; Nord and Young, 1975; Sessle and Greenwood, 1976; Yokota, 1975, 1976; Yokota et al., 1996). On the other hand, only a few brainstem tooth pulp neurons that are activated by natural stimuli of tooth have been recorded (Hu and Sessle, 1984).

The location of neurons within the medullary dorsal horn that respond to natural noxious stimulation of the dentition is largely unknown. Although several studies have identified the neurons that respond to thermal stimulation of the cutaneous receptive fields (Craig and Dostrovsky, 1991; Dickenson et al., 1979; Dostrovsky and Hellon, 1978; Maixner et al., 1989), few have examined the medullary tooth pulp neurons that respond to thermal stimuli of tooth (Hu and Sessle, 1984). Our laboratory (Chattipakorn, 1999) has also shown that the application of noxious heat by a conventional device to the intact ferret canine induces the expression of the early-immediate gene product $c$-Fos within the neurons located in spatially distinct regions of the trigeminal sensory complex. However, there is limited data on response of tooth pulp neurons to natural stimuli of tooth, such as heat. A major difficulty in identifying such neurons has been the lack of a device that allows controlled stimulation of the intact dentition. In this study, a dual use thermal and electrical stimulator that can activate neurons in the medullary dorsal horn that receives input from the dental pulp, was developed and tested.

\section{Materials and Methods}

\subsection{General description of stimulator}

Figure 1 shows the overall design of the stimulator. The device consists of four outputs that can deliver either electrical or thermal stimuli to the four canines. During a stimulation period, only one stimulus (electrical or thermal) can be delivered to a tooth. The system can monitor the electrical impedance of the stimulated tooth. In normal use, four stimulating probes were positioned over the canines, cemented in place with colloidal silver liquid (No. 16031, TED PELLA Inc) and connected to the controller that allows the delivery of thermal and electrical stimuli and the monitoring of the tooth's impedance. The controller permits only one probe to be stimulated at one time. Between the delivery of thermal stimuli, electrical stimuli can be delivered or be used to monitor the impedance of the tooth. Electrical stimuli can be delivered using a commercially available electrical stimulator connected to the frontal panel on the control device via banana type jacks (see Fig. 1).

Thermal stimuli are generated at the thermode tips by passing a controlled current through a nickel-cadmium wire wrapped around the brass cylinder probe (Fig. 2). The temperature is monitored using a ' $\mathrm{K}$ ' type thermocouple amplified and fed back to the driver circuit that regulates the current and associated temperature of the probe. The probe consists of a brass cylinder that is eight millimeters in length and two millimeters in internal diameter. In order for the probe to conform to the anatomy of the ferret's canine, it is reshaped to a conical form. An electrical wire is soldered to the cylinder which permits the delivery of electrical 
stimuli and monitoring of the electrodes' impedance. An insulated nickel-cadmium heater wire is also wrapped around the cylinder, which permits the delivery of thermal stimuli. A ' $\mathrm{K}$ ' type thermocouple is bonded to the cylinder with a heat conductive epoxy. All the components are held together with the same epoxy. The probe is then insulated thermally by applying a coat of regular epoxy.

An 'Analog Devices' monolithic thermocouple amplifier with cold junction compensation (AD595CQ) is wired directly to the thermocouple wire inside a 9 pin D shell connector. Figure 3 shows a schematic circuit diagram of the main circuit board associated with the controlling unit. The amplifier provides an output rated at $10 \mathrm{mV}$ per ${ }^{\circ} \mathrm{C}$. The output from the thermocouple amplifier is re-amplified by a factor of 10 to obtain an output of $100 \mathrm{mV}$ per ${ }^{\circ} \mathrm{C}$ with a range up to $100^{\circ} \mathrm{C}(10$ volts $)$. The gain and offset of this amplifier are adjusted to improve the accuracy of temperature control and temperature output. An optional 5-volt offset was added to accommodate commercially available analog to digital converters with a fixed range of \pm 5 volts. For the same reason, the controller temperature command also has an optional 5 volt offset. In addition, the input command has both gain and offset adjustments, which allows tuning of the probe temperature. The comparator output controlled by the temperature command from CED 1401 is fed into a current driver that can be adjusted for optimal operation: a current large enough for rapid temperature ramps without causing an excessive overshot.

\subsection{Animal preparation for electrophysiological recordings}

A set of animal studies were conducted to validate the specifications and operating characteristics of the device. All procedures involving the use of animals were approved by the Institutional Animal Care and Use Committee of the University of North Carolina at Chapel Hill. The experiments were carried out on 18 adult male ferrets (mustela utorius furo ) weighing $0.9-1.4 \mathrm{~kg}$. An in vitro study was conducted on the extracted canines placed in $37^{\circ} \mathrm{C}$ water bath $(\mathrm{N}=6)$. The animals were anesthetized with $3 \%$ halothane with oxygen for induction, followed by a mixture of chloral hydrate $(110 \mathrm{mg} / \mathrm{kg})$ and pentobarbital sodium $(20 \mathrm{mg} / \mathrm{kg})$ intraperitoneally. Anesthesia was maintained with periodic intravenous injections of a mixture of chloral hydrate $(22 \mathrm{mg} / \mathrm{kg})$ and pentobarbital sodium $(4 \mathrm{mg} / \mathrm{kg})$. The arterial blood pressure and body temperature were monitored continuously in each animal and were maintained at $90-120 \mathrm{mmHg}$ and $37^{\circ} \mathrm{C}-38^{\circ} \mathrm{C}$, respectively. The animals were placed in a stereotaxic frame, neck muscles were dissected away, and the dura overlying the medullary surface was removed to expose the obex and medulla. The exposed surface of the medulla was covered with warm saline. During recording, the animals were immobilized with Vecuronium bromide $(0.4 \mathrm{mg} / \mathrm{kg})$ and ventilated artificially through a tracheal cannula. The end tidal $\mathrm{CO}_{2}$ level was maintained at $3.5-4.5 \%$.

\subsection{Tooth preparation for stimulation}

The upper and lower canines were prepared for both electrical and heat stimulation. The computer-controlled probe was placed over the clinical crown. This device can deliver constant electrical or noxious heat stimuli. The cathode electrode was connected to the maxillary and mandibular canines, and an anode electrode was positioned on a neck muscle. The stimulating probe was secured to each canine with colloidal silver liquid (No. 16031, TED PELLA Inc). The canines were isolated further from the remainder of the oral cavity by gently placing a dental rubber damn around the tooth to prevent unintentional stimulation to the adjacent intra-oral tissues.

\subsection{Extracellular recording of tooth pulp neurons}

Extracellular recordings were made with glass electrodes with a resistance of 2-10 M $\Omega$. The electrode was advanced into the trigeminal nucleus caudalis with a microdrive, and the 
recording depths and location relative to the surface of the brainstem and obex were noted. In general, the first penetration was 1.8 to $2.3 \mathrm{~mm}$ lateral to the midline at the level of the obex. This area has shown dense c-Fos expression following noxious thermal stimulation of the maxillary and mandibular canines in ferrets (Chattipakorn, 1999). The single unit activity was amplified and fed to a window discriminator, audio monitor, and displayed on an oscilloscope. In addition, the discriminated spikes were sent to a digital interface (CED 1401) and computer for on-line or offline analysis and storage.

The tooth pulp neurons that responded to thermal stimulation of tooth were characterized further by testing the convergence from cutaneous fields with non-noxious tactile stimuli (Von Frey filaments and soft brushes) and noxious stimuli (pinch with a toothed forcep, contact heat and cold). Tooth pulp neurons with cutaneous receptive fields were classified as either low threshold mechano-receptive neurons (LTM), wide dynamic range neurons (WDR), or nociceptive-specific neurons (NS) (Bossut and Maixner, 1996; Dubner and Bennett, 1983).

\subsection{Electrical and noxious heat stimulation of the teeth}

Constant current square wave pulses ( $2 \mathrm{msec}$ duration) were delivered to a tooth once every second as a search stimulus by a computer-controlled probe. Delivered current was continuously monitored by assessing the voltage drop across a 100-ohm resistance in series with the preparation. In order to prevent stimulation of the adjacent tissues the intensity of the applied current did not exceed $150-200 \mu \mathrm{A}$, as described previously (Mattews and Searle, 1976).

Electrical stimulation was also used to determine the latency times for the primary afferent input to the recorded neurons. Single units were also examined for responses to input from A-fiber and C-fiber primary afferents using standard techniques as described previously (Bossut and Maixner, 1996; Hu et al., 1981; Price et al., 1976). Minimum conduction velocity was determined by post-stimulus histogram constructed from successive 50 consecutive electrical pulses delivered to tooth pulp. Latency values were corrected for a 0.5 msec synaptic delay and conduction distances were estimated by measuring the length of a thread positioned along the primary afferent route. Neuronal responses with estimated conduction velocities greater than $2 \mathrm{~m} / \mathrm{sec}$ were assumed to receive A-fiber afferent input and those with estimated conduction velocities less than $2 \mathrm{~m} / \mathrm{sec}$ were assumed to receive Cfiber afferent input.

Assessment of sensitivity to quantitative heat stimuli was carried out with the custom designed computer-controlled contact thermode described above. Heat stimuli were applied in a staircase manner from an adapting temperature of $40^{\circ} \mathrm{C}$, and increasing to $65^{\circ} \mathrm{C}$ in $5^{\circ} \mathrm{C}$ increments every 25 seconds or as a single thermal pulse for $60 \mathrm{sec}$. We have previously determined that these stimulation parameters result in an intra-pulpal temperature of $43{ }^{\circ} \mathrm{C}$ with an elevation rate $<1{ }^{\circ} \mathrm{C} / \mathrm{sec}$ in vitro (Chattipakorn et al., 1999).

\subsection{Histological procedure}

After the experiment, the animal was sacrificed with an overdose of pentobarbital sodium. Cardiac perfusion was performed with $0.01 \mathrm{M}$ phosphate buffered saline (PBS) followed by $10 \%$ formaldehyde fixative in $0.01 \mathrm{M}$ PBS. After perfusion, the brainstem was removed and the trigeminal nuclear complex was blocked, post fixed in $10 \%$ formaldehyde for approximately 24 hours, and then placed in 30\% sucrose in 0.01 M PBS for three days. The tissue was processed at $60 \mu \mathrm{m}$ sections (frozen sections). The histological sections were mounted on gelatin slides and stained with cresyl violet to confirm the recording sites. 


\section{Results}

Prior to the in vivo studies, an in vitro study was conducted on extracted canines placed in a $37^{\circ} \mathrm{C}$ water bath to determine the effects of thermal stimulation to the intact tooth on the intra-pulpal temperatures. Heat stimuli were applied to the extracted tooth in a staircase manner from a first-adapting temperature of $40^{\circ} \mathrm{C}$ and increasing to $65^{\circ} \mathrm{C}$ in $5^{\circ} \mathrm{C}$ increments every 25 seconds, which resulted in an intrapulpal temperature of $43.6 \pm 0.6^{\circ} \mathrm{C}$ at a rate of $<$ $1{ }^{\circ} \mathrm{C} / \mathrm{sec}$ (Fig. 4). Heat stimuli applied to the extracted tooth as a single pulse of a $60^{\circ} \mathrm{C}$ stimulus for 60 seconds increased the pulpal temperature to $43.1 \pm 0.7^{\circ} \mathrm{C}$ at a rate of $<1^{\circ} \mathrm{C} /$ sec (Fig. 4).

One hundred and fifty three neurons excited by electrical stimulation of the canines were recorded. However, only 15\% (23 neurons) of the cells responded to both electrical stimulation and noxious heat stimulation. Figure 5 shows a typical firing pattern of a tooth pulp neuron that responded to noxious heat stimuli of tooth pulp. This neuron responded to noxious heat when the pulpal temperature exceeded $40^{\circ} \mathrm{C}$. Figure 6 gives an example of a typical response of a neuron activated by right canine thermal stimulation. This neuron, which had a cutaneous receptive field on the facial area, was located in lamina V (Fig. 6A). Electrical stimulation of the tooth with 50 successive pulses $(2 \mathrm{msec}$ duration delivered at 1 $\mathrm{Hz}, 100 \mu \mathrm{A}$ ) evoked afferent responses between 5 and $10 \mathrm{msec}$, which is consistent with the A $\delta$ fiber input (Fig. 6B). This neuron responded to both noxious (pinch) and non-noxious (brush) stimulation of the cutaneous receptive field and was classified as a WDR neuron. The neuron was also excited by noxious heat stimulation of the tooth (Fig. 6C). All 23 tooth pulp neurons that respond to heat stimuli of canine had cutaneous receptive fields and were classified based on their responses to noxious and non-noxious stimulation of their cutaneous receptive fields. Eight neurons responded only to noxious stimulation of the cutaneous receptive fields and were classified as NS neurons, and 15 responded to both noxious and non-noxious stimulation and were classified as WDR neurons. Twelve neurons were located in the superficial laminae and 11 neurons were located in the deep laminae in the subnucleus caudalis $(\mathrm{Vc})$ and the interface between the nucleus caudalis and nucleus interpolaris $(\mathrm{Vc} / \mathrm{Vi})$.

\section{Discussion}

This paper reports a novel system that allows the electrical and thermal stimulation of the intact tooth using a computer-controlled device. Electrical stimuli can be delivered with commercially available electrical stimulators. The electrical signal from the ' $\mathrm{K}$ ' type thermocouple is amplified and feed back to the driver circuit, which controls the magnitude and the rate of increase in thermal stimulus. A CED programmable data acquisition system was used to send the temperature commands and record the actual temperature of the thermodes. The CED output, which has a range of $-5 \mathrm{~V} \mathrm{DC}$ to $+5 \mathrm{~V} \mathrm{DC}$, is interpreted by the external unit as a temperature command with a range of $0^{\circ} \mathrm{C}$ to $100^{\circ} \mathrm{C}$ and the output is amplified by Analog Devices AD595CQ monolithic thermocouple amplifiers. The actual temperature of thermodes is measured by means of $\mathrm{K}$ type thermocouples (chromel-alumel). Both the command and thermode temperature signals are conditioned through two Analog Devices AD620 instrument amplifiers, the outputs of which are compared and their difference is used to adjust the thermode heating element current. Analog signals can be fed to a digital converter for computer display and the storage of digital signals.

The present study first examined the ability of externally applied thermal stimuli to increase the intrapulpal temperatures on extracted canines placed in a $37^{\circ} \mathrm{C}$ water bath. Heat stimulation applied to the canine in a staircase manner from an adapting temperature of $40^{\circ} \mathrm{C}$ to $65^{\circ} \mathrm{C}$ in $5^{\circ} \mathrm{C}$ increments every 25 seconds increased the pulpal temperature above 
$43^{\circ} \mathrm{C}$ at a rate of $<1^{\circ} \mathrm{C} / \mathrm{sec}$. The application of a single pulse of $60^{\circ} \mathrm{C}$ for 60 seconds also increased the pulpal temperature above $43^{\circ} \mathrm{C}$. Previous studies have shown that a pulpal temperatures above $42^{\circ} \mathrm{C}$ stimulates the pulpal C fibers (Narhi et al., 1982) and invoke the expression of the early immediate gene, $c$-Fos protein, in the specific regions of the trigeminal nucleus (Chattipakorn, 1999). These results demonstrate that this device can activate pulpal afferents that contribute to pulpal pain.

An electrophysiological study also demonstrated that the stimulation device can evoke both electrical and thermal responses from the neurons that receive pulpal afferent input. Consistent with previous studies (Hu and Sessle, 1984) only a small percentage of trigeminal neurons that responded to the electrical stimulation of the dentition also responded to thermal stimuli of tooth. These results suggest that electrical stimulation of the tooth produces the non-selective activation of trigeminal cells and that the majority of these cells $(\sim 85 \%)$ do not respond to natural noxious stimuli applied to the dentition.

Twenty three neurons that responded to noxious thermal stimulation of the dentition were recorded. All neurons were observed in both the superficial and deep nuclear regions of the subnucleus caudalis $(\mathrm{Vc})$ and the interface between the nucleus caudalis and nucleus interpolaris $(\mathrm{Vc} / \mathrm{Vi})$. This result is consistent with the previous findings showing that expressions of the early immediate gene, $c$-Fos, in response to noxious heat stimulation of the canine are located in these regions (Chattipakorn, 1999). The largest clusters of Fos positive neurons are found in the superficial laminae and deep regions at the level of obex. Similar to previous electrophysiological studies, the present study also observed that a large number of tooth pulp neurons responded to the electrical stimulation of the tooth (Nord, 1976; Nord and Young, 1975; Yokota, 1975, 1976; Yokota et al., 1996). The cells that responded to electrical stimulation of the canine are densely concentrated in the trigeminal complex at the level of obex. However, most neurons that responded to electrical stimulation of the tooth pulp did not respond to noxious heat stimulation of the tooth in the present study. These results suggest that the electrical stimulation of tooth produces the nonselective activation of trigeminal neurons that respond to pulpal stimulation and that electrical stimulation of the dentition does not engage processes that mimic the events that produce dental pain evoked under clinical or natural conditions.

The central trigeminal neurons receive convergent input from the dentition and nearby cutaneous or mucosal receptive fields (Robinson, 1979; Sessle et al., 1986). Dental pain is poorly localized, because it is difficult for patients to identify the tooth of origin associated with symptomatic pulpitis (i.e., toothache; Friend and Glenwright, 1968). The extensive convergence of the afferent input to central trigeminal neurons is a likely central mechanism that mediates the diffuse nature of pulpal pain. In the present study, tooth pulp neurons that responded to thermal stimulation received convergent input from the cutaneous fields. The cells that responded to noxious heat stimulation of the tooth were classified as either NS or WDR neurons based on their response to the stimuli applied to their cutaneous receptive fields. These results suggest that tooth pulp neurons with sensory convergence from the cutaneous receptive fields provide evidence for the poor localization of pulpal pain.

This computerized thermal stimulator system can deliver both electrical and thermal stimulation in ferret canine teeth, but not cold stimulation. Therefore, this system requires a computerized cold stimulation in a future study. Ferret canine teeth were used for electrical or thermal stimulation. When electrical stimulation was applied to rat incisor, the current may spread out beyond a tooth pulp (Myslinski and Matthews, 1987) because the root of incisor has a wide open shape. Therefore, ferret canine teeth are used frequently for electrical (Oakden and Boissonade, 1998) or thermal stimulation (Chattipakorn et al., 1999). 
Moreover, this computerized thermal stimulator system might allow tooth stimulation in rats or dogs because we can adjust the shape of a computer-controlled probe.

In summary, this study has developed a combined computer-controlled thermal/electrical stimulator that allows the quantitative stimulation of the dental pulp with a natural stimulus in a manner that does not require an invasion of the tooth. This device will prove useful in studies designed to assess the peripheral and central pathways that convey noxious sensory information from the dentition.

\section{Highlights}

We have developed a novel computer-controlled thermal/electrical stimulator that permits the quantitative stimulation of the dental pulp with a natural stimulus. This new device is able to accurately deliver both thermal and electrical stimuli to the intact tooth. Only $15 \%$ of the neurons activated by electrical stimulation responded to noxious heat applied to the canine.

\section{Acknowledgments}

This study was supported by DE 11661 from NIDCR to Dr. W. Maixner.

\section{References}

Anderson DJ, Hannam AG, Mathews B. Sensory mechanisms in mammalian teeth and their supporting structures. Physiol. Rev. 1970; 50:171-195. [PubMed: 4908088]

Bossut DF, Maixner W. Effects of cardiac vagal afferent electrostimulation on the responses of trigeminal and trigeminothalamic neurons to noxious orofacial stimulation. Pain. 1996; 65:101-109. [PubMed: 8826496]

Chattipakorn SC, Light AR, Willcockson HH, Narhi M, Maixner W. The effect of fentanyl on c-fos expression in the trigeminal brainstem complex produced by pulpal heat stimulation in the ferret. Pain. 1999; 82:207-215. [PubMed: 10467925]

Craig AD, Dostrovsky JO. Thermoreceptive lamina I trigeminothalamic neurons project to the nucleus submedius in the cat. Exp. Brain Res. 1991; 85:470-474. [PubMed: 1716595]

Dickenson AH, Hellon RF, Taylor DC. Facial thermal input to the trigeminal spinal nucleus of rabbits and rats. J. Comp. Neurol. 1979; 185:203-209. [PubMed: 429614]

Dostrovsky JO, Hellon RF. The representation of facial temperature in the caudal trigeminal nucleus of the cat. J. Physiol. 1978; 277:29-47. [PubMed: 650531]

Dubner R, Bennett GJ. Spinal and trigeminal mechanisms of nociception. Annu. Rev. Neurosci. 1983; 6:381-418. [PubMed: 6132587]

Friend LA, Glenwright HD. An experimental investigation into the localization of pain from the dental pulp. Oral. Surg. Oral. Med. Oral. Pathol. 1968; 25:765-774. [PubMed: 5239099]

Hu JW, Dostrovsky JO, Sessle BJ. Functional properties of neurons in cat trigeminal subnucleus caudalis (medullary dorsal horn). I. Responses to oral-facial noxious and nonnoxious stimuli and projections to thalamus and subnucleus oralis. J. Neurophysiol. 1981; 45:173-192. [PubMed: 7463102]

Hu JW, Sessle BJ. Comparison of responses of cutaneous nociceptive and nonnociceptive brain stem neurons in trigeminal subnucleus caudalis (medullary dorsal horn) and subnucleus oralis to natural and electrical stimulation of tooth pulp. J. Neurophysiol. 1984; 52:39-53. [PubMed: 6747677]

Maixner W, Dubner R, Kenshalo DR Jr, Bushnell MC, Oliveras JL. Responses of monkey medullary dorsal horn neurons during the detection of noxious heat stimuli. J. Neurophysiol. 1989; 62:437449. [PubMed: 2769340]

Matthews B. Responses of intradental nerves to electrical and thermal stimulation of teeth in dogs. J. Physiol. 1977; 264:641-664. [PubMed: 557544] 
Matthews B, Searle BN. Electrical stimulation of teeth. Pain. 1976; 2:245-251. [PubMed: 1026902]

Myslinski N, Matthews B. Intrapulpal nerve stimulation in the rat. J. Neurosci. Methods. 1987; 22:7378. [PubMed: 3695570]

Närhi M, Jyväsjärvi E, Hirvonen T, Huopaniemi T. Activation of heat-sensitive nerve fibres in the dental pulp of the cat. Pain. 1982; 14:317-326. [PubMed: 7162836]

Naylor, MN. Sensory mechanisms in dentine. Oxford: Pergamon Press; 1963. Studies on the mechanism of sensation to cold stimulation of human dentine; p. 80-87.

Nord SG. Electrical stimulation of the tooth pulp in the study of pain. Brain Res. Bull. 1976; 1:251254. [PubMed: 974804]

Nord SG, Young RF. Projection of tooth pulp afferents to the cat trigeminal nucleus caudalis. Brain Res. 1975; 90:195-204. [PubMed: 1139303]

Oakden EL, Boissonade FM. Fos expression in the ferret trigeminal nuclear complex following tooth pulp stimulation. Neuroscience. 1988; 84:1197-1208. [PubMed: 9578406]

Price DD, Dubner R, Hu JW. Trigeminothalamic neurons in nucleus caudalis responsive to tactile, thermal, and nociceptive stimulation of monkey's face. J. Neurophysiol. 1976; 39:936-953. [PubMed: 824411]

Robinson PP. The course, relations and distribution of the inferior alveolar nerve and its branches in the cat. Anat. Rec. 1979; 195:265-271. [PubMed: 507391]

Sessle BJ. The neurobiology of facial and dental pain: present knowledge, future directions. J. Dent. Res. 1987; 66:962-981. [PubMed: 3301935]

Sessle BJ, Greenwood LF. Inputs to trigeminal brain stem neurones from facial, oral, tooth pulp and pharyngolaryngeal tissues: I. Responses to innocuous and noxious stimuli. Brain Res. 1976; 117:211-226. [PubMed: 990915]

Sessle BJ, Hu JW, Amano N, Zhong G. Convergence of cutaneous, tooth pulp, visceral, neck and muscle afferents onto nociceptive and non-nociceptive neurons in trigeminal subnucleus caudalis (medullary dorsal horn) and its implications for referred pain. Pain. 1986; 27:219-235. [PubMed: 3797017]

Yokota T. Excitation of units in marginal rim of trigeminal subnucleus caudalis elicited by tooth pulp stimulation. Brain Res. 1975; 95:154-158. [PubMed: 1156864]

Yokota T. Two types of tooth pulp units in the bulbar lateral reticular formation. Brain Res. 1976; 104:325-329. [PubMed: 1260429]

Yokota T, Nishikawa Y, Koyama N, Fujino Y. Differential distribution of four types of tooth pulp neurons in the caudal medulla oblongata of the cat. Brain Res. 1996; 715:230-234. [PubMed: 8739644] 


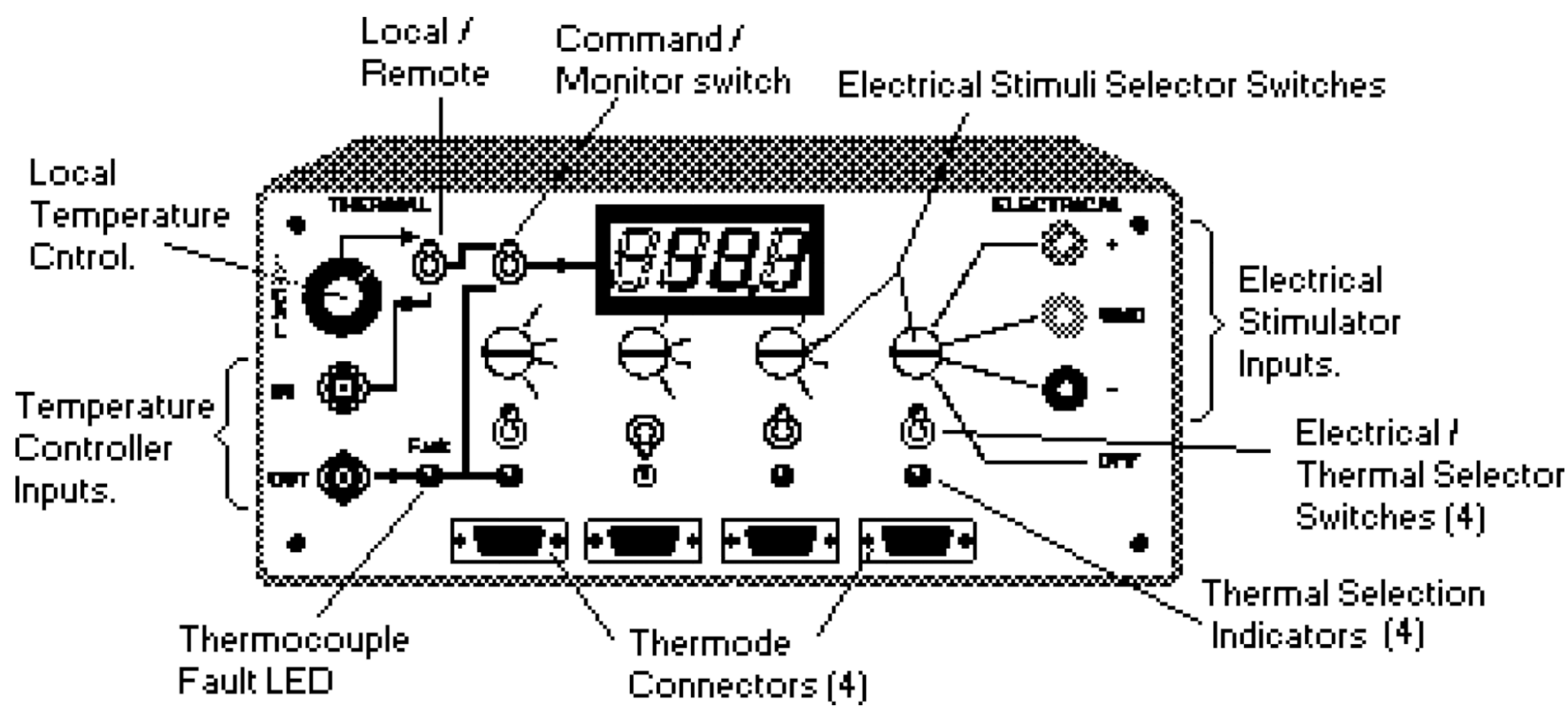

Figure 1.

Diagram of the overall design of a stimulator. The device consists of four outputs that can deliver either thermal or electrical stimulus to four canines. The left side of the unit controls the thermal stimuli. The right side of the unit contains ports for the attachment of an electrical stimulator. The center of the unit controls and monitors the components that allow the selection of either electrical or thermal stimulation. The large LED panel displays either temperature or impedance values. 
A
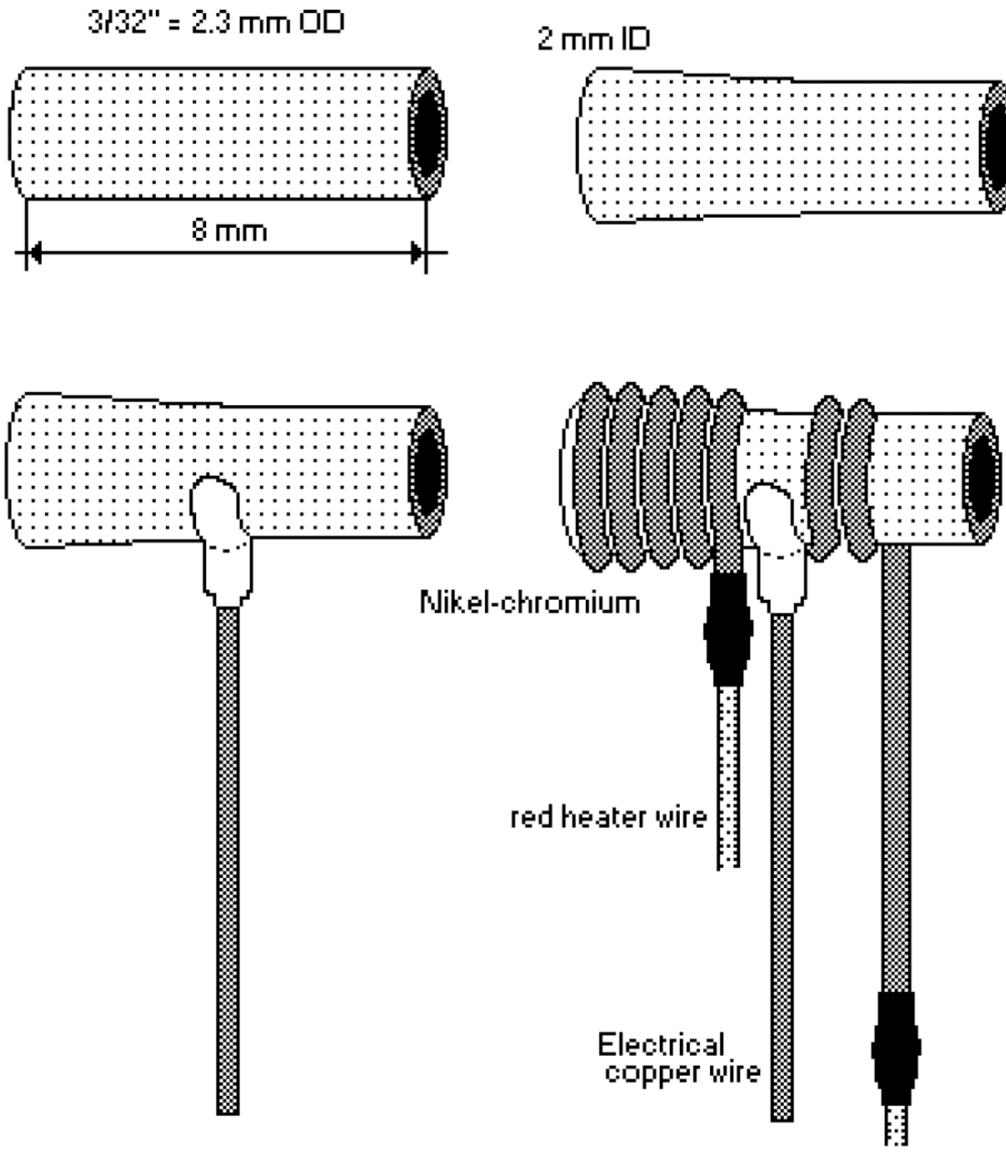

B

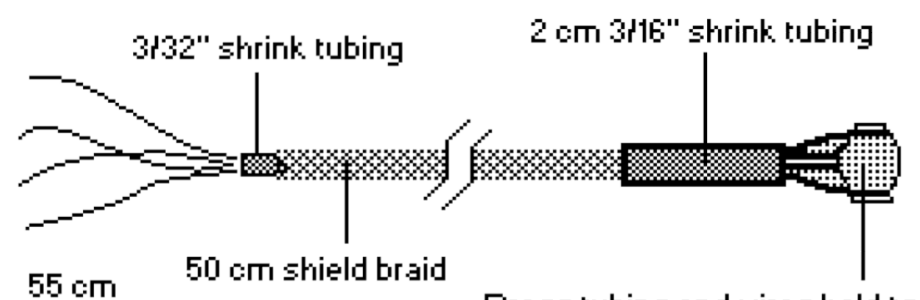

Brass tubing and wires held together with heat conductive blue epony

Figure 2.

Diagram of the components of the thermal/electrical probe. $\boldsymbol{A}$, Schematic diagram of the internal components of the tip assembly. $\boldsymbol{B}$, Diagram of a fully constructed probe and cable. 


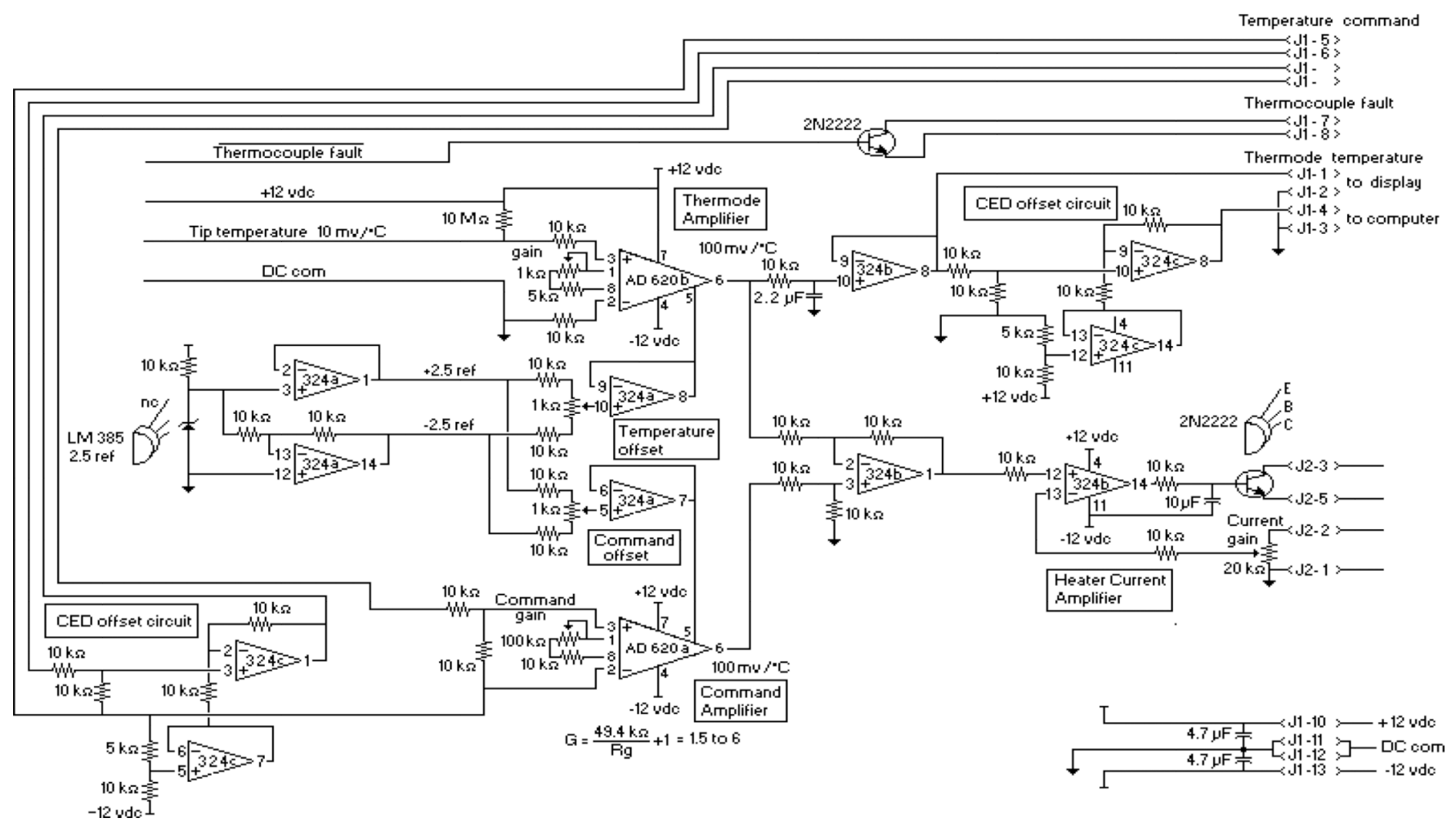

Figure 3.

Schematic circuit diagram of the main circuit board associated with the controlling unit. 

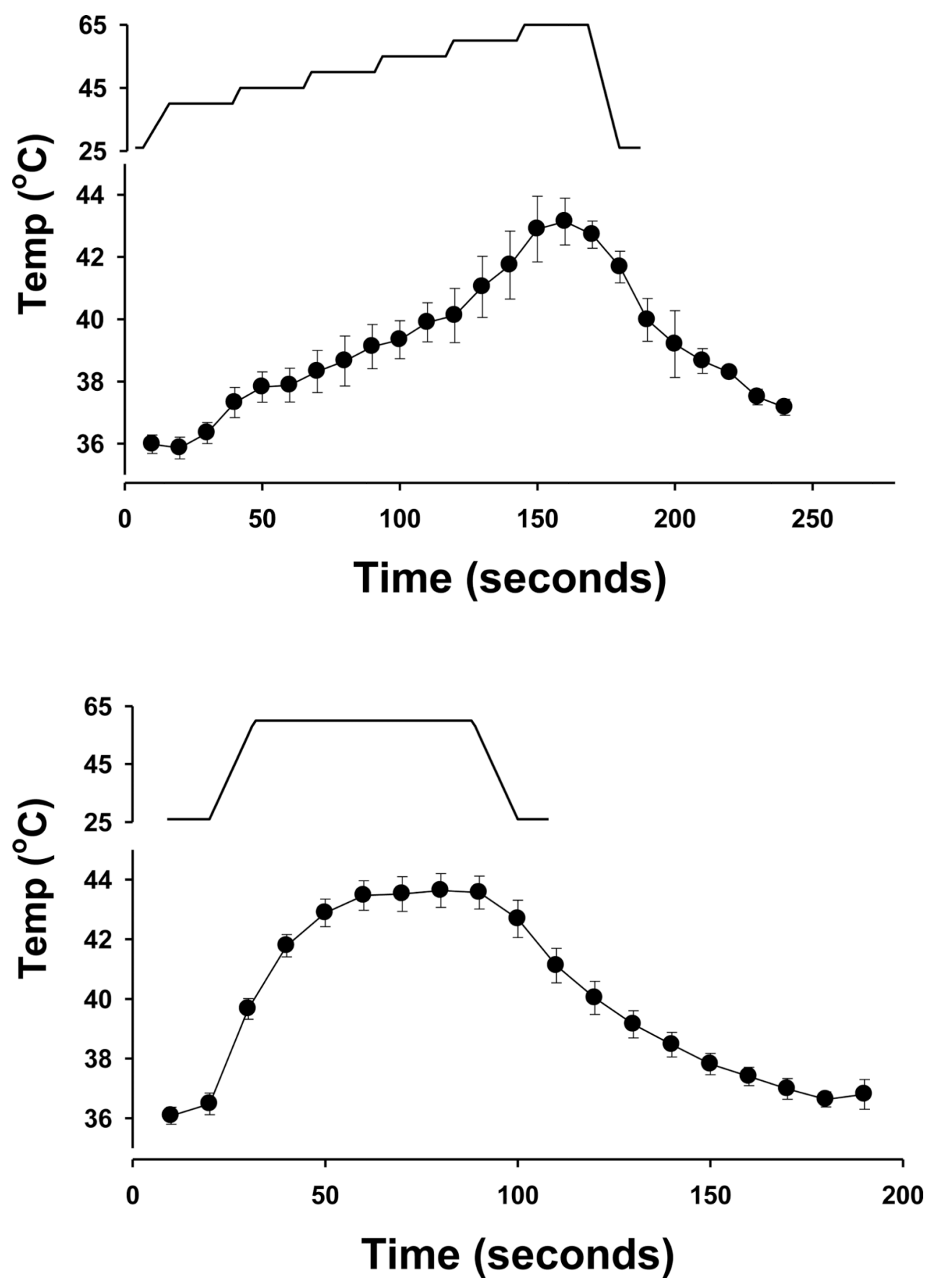

Figure 4.

Effect of sustained heat stimulus applied to the external surface of the intact teeth on the intra-pulpal temperature. Heat stimuli were applied to the extracted tooth in a staircase manner from an adapting temperature of $40^{\circ} \mathrm{C}$, increasing to $65^{\circ} \mathrm{C}$ in $5^{\circ} \mathrm{C}$ increments every 25 seconds or increasing to $60^{\circ} \mathrm{C}$ for 60 seconds, which resulted in an intrapulpal temperature over $43^{\circ} \mathrm{C}$ at rate of $<1^{\circ} \mathrm{C} / \mathrm{sec}(\mathrm{N}=6)$. Values are expressed as mean $\pm \mathrm{SEM}$. 


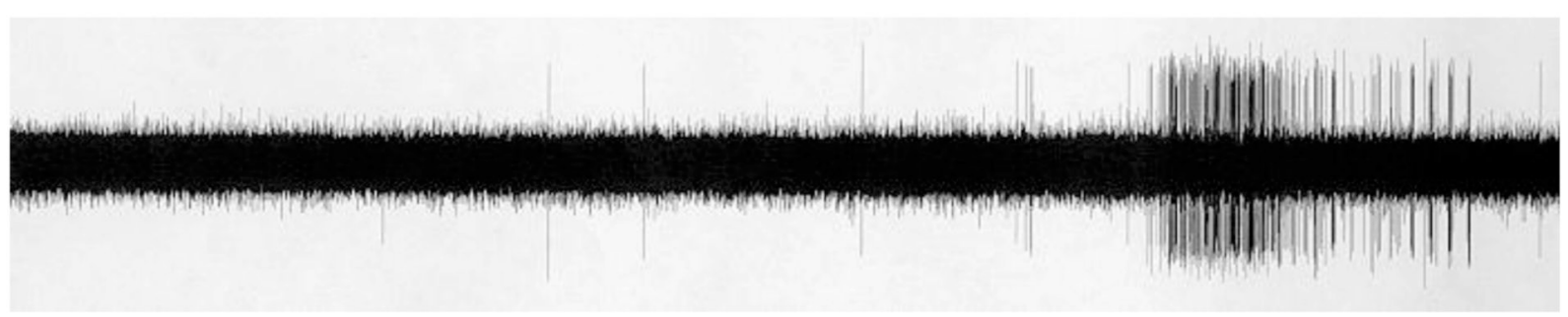

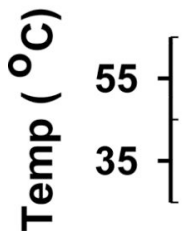

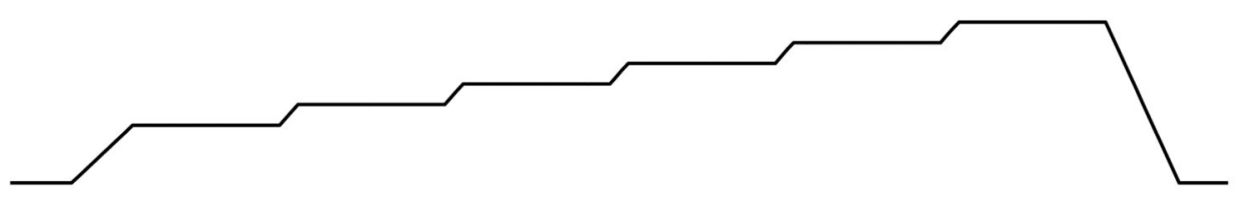

Figure 5.

Typical firing pattern of a tooth pulp neuron that responded to noxious heat stimuli applied to the canine from an adapting temperature of $40^{\circ} \mathrm{C}$, increasing to $65^{\circ} \mathrm{C}$ in $5^{\circ} \mathrm{C}$ increments every 25 seconds. 
A

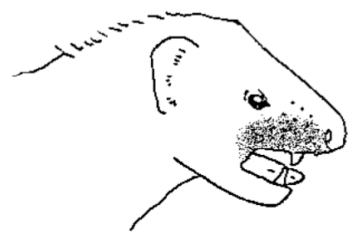

C

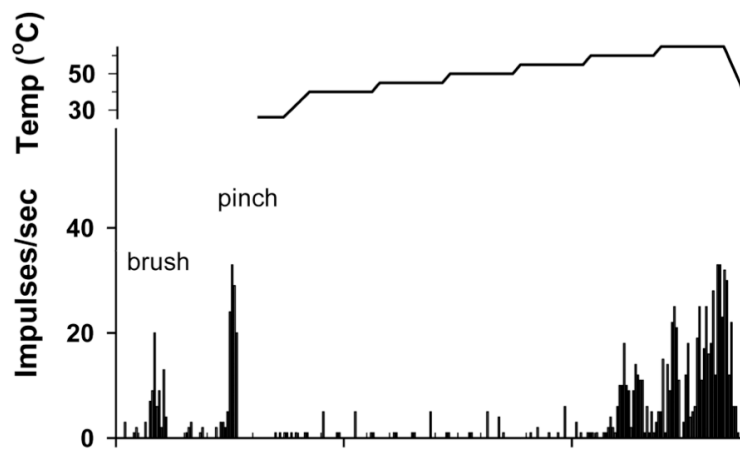

B

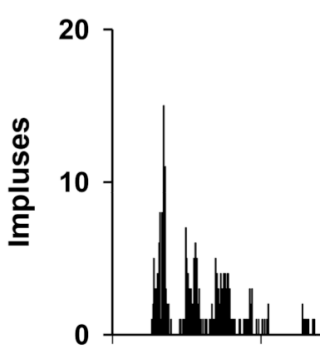

20

Latency (msec)

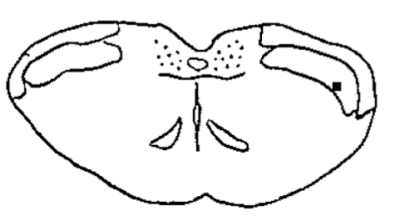

0 - 0

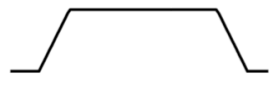

40

Figure 6.

Representative example of a tooth pulp neuron that responded to noxious heat stimulation of canine. $\boldsymbol{A}$, The cutaneous receptive field and camera lucida drawing that shows the location of the recorded neuron. This cell had a cutaneous receptive field that was located on the right face and upper lip. The cell was classified as a WDR neuron. $\boldsymbol{B}$, Peristimulus histogram to electrical stimulation of the tooth (50 presentations). The neuron received an A $\delta$ afferent input. $\boldsymbol{C}$, Responses to noxious heat stimulation of the canine. 